\section{Narrativas incendiárias: Remix, Estética e Diferença em Little Fires Everywhere}

Pedro de Assis Pereira Scudeller ${ }^{(1)}$ e Dariane Lima Arantes ${ }^{(2)}$

Resumo: Este artigo propõe, a partir de uma análise comparativa entre o best-seller Little Fires Everywhere e sua adaptação para a televisão, tensionar os sentidos relacionados a marcadores de gênero, raça e classe presentes em suas narrativas. Procuramos compreender como as narrativas da diferença são incorporadas e negociadas nessas obras, a partir de reflexões sobre a cultura remix, e identificar em que medida as narrativas revelam regimes de visibilidade e se tornam operadoras de dissenso, estabelecendo uma política de diferença em relação às representações femininas. Pensamos aqui nas interseções entre a experiência estética, a cultura midiática e as representações da diferença.

Palavras chave: audiovisibilidades - cultura remix - representações da diferença - partilha do sensível - Little Fires Everywhere.

[Resumos em espanhol e inglês nas páginas 165-166]

(1) Pedro de Assis Pereira Scudeller: Doutorando no Programa de Pós Graduação em Comunicação e Práticas do Consumo da Escola Superior de Propaganda e Marketing (Bolsista CAPES - PROSUP INTEGRAL). Mestre em Comunicação e Práticas do Consumo pela ESPM-SP. Membro do grupo de pesquisa Culturas juvenis: comunicação, política e consumo (Juvenália). Pesquisador associado na rede de investigação latino-americana CLACSO, no GT Infancias y Juventudes. Mail: pedroscudeller@gmail.com.

(2) Dariane Lima Arantes. Doutoranda no Programa de Pós Graduação em Comunicação e Práticas do Consumo da Escola Superior de Propaganda e Marketing (Bolsista CAPES - PROSUP INTEGRAL). Mestre em Comunicação e Práticas do Consumo pela ESPM-SP. Membro do grupo de pesquisa Culturas juvenis: comunicação, política e consumo (Juvenália). Pesquisadora associada na rede de investigação latino-americana CLACSO, no GT Infancias y Juventudes. Mail: dariane_arantes@yahoo.com.br. 


\section{Introcução ${ }^{1}$}

Em maio de 2020, a série Little Fires Everywhere fez sua estreia no serviço de streaming da Amazon Prime Video. Adaptação do romance best-seller de mesmo nome, escrito pela autora Celeste Ng e lançado em 2017, a produção audiovisual obteve impacto social e midiático relevantes ao tratar de conflitos de classe, raça, além de questões de gênero como machismo, sexualidade feminina e maternidade.

Destacamos que a produção audiovisual se diferencia da obra literária em importantes aspectos. No livro, Mia Warren não é descrita como uma mulher negra, uma das maiores alterações entre as histórias. No romance, o foco se estabelece nas relações de poder entre duas mulheres de diferentes realidades sociais. $\mathrm{Na}$ série, as questões raciais se tornam o centro da narrativa e o debate envolvendo questões de classe se complexifica, atrelando-se ainda a questões que envolvem diferentes perspectivas sobre as formas de se ser mulher e de se exercer a maternidade.

A narrativa é centrada na vivência de duas mulheres muito distintas, Elena, interpretada pela atriz Reese Whiterspoon, branca, rica, casada, jornalista e mãe de quatro filhos e Mia, vivida por Kerry Washington, negra, solteira, artista plástica e mãe de uma adolescente. $\mathrm{O}$ destino de ambas se entrelaça quando as personagens passam a conviver em um mesmo bairro de uma cidade chamada Shaker Heights. Longe de abordar representações maniqueístas, as protagonistas são mulheres complexas, que articulam, pela via da interseccionalidade, dinâmicas que envolvem múltiplos sistemas de opressão e denotam à inseparabilidade entre racismo estrutural, capitalismo e patriarcado.

A perspectiva interseccional configura-se como um marcador teórico-metodológico essencial a investigação proposta neste artigo. Isto porque, enquanto direcionamento reflexivo e ferramenta analítica, nos possibilita subsídios para elucidar a complexidade das relações sociais contemporâneas, no contexto de intensa globalização e fluxos migratórios. Ao considerar que as categorias de raça, gênero, classe, faixa etária, nacionalidade, orientação sexual se moldam mutuamente, Collins e Bilge (2020) veem a interseccionalidade com importante instância investigativa das relações de poder e de suas influências nas interações em sociedades marcadas pela diversidade, bem como seus efeitos nas experiências individuais cotidianas.

A partir do exposto, o artigo se propõe a refletir sobre os sentidos e tensões relacionados a marcadores de gênero, raça e classe, a partir de uma análise comparativa entre o bestseller Little Fires Everywhere e sua adaptação para a televisão. Nossa problemática está centrada em compreender, a partir da representação das protagonistas Elena Richardson e Mia Warren, como as narrativas da diferença são incorporadas e negociadas nestas obras, tendo em vista os embates raciais e de gênero que envolvem as personagens. Objetiva-se identificar em que medida tais narrativas desvelam regimes de visibilidade e tornam-se operadoras de dissenso, estabelecendo uma política da diferença no que concerne à representação de personagens femininos.

Dispomos dos conceitos de cultura remix (Navas, 2012; Manovich, 2001, 2005), da dimensão fabulativa das narrativas do entretenimento de Omar Rincón (2006) além das reflexões sobre tecnologia e estética de Denise Guimarães (2007) para analisar os processos de significação contidos na obra literária Little Fires Everywhere e em sua versão audiovisual. 
Tal escolha, se justifica por concebermos tanto a obra literária quanto a produção audiovisual como lugares potenciais para a construção de debates em torno das discussões sobre gênero, privilégios de classe, representações e raça. Como direcionamento metodológico, utilizamos as reflexões sobre partilha do sensível, proposta por Jacques Rancière (2005), para pensar as intersecções entre experiência estética, cultura midiática e representações da diferença.

\section{O potencial estético e político das audiovisualidades em contextos midiáticos}

Para Jacques Rancière (2005) a estética é entendida como experiência, inserida no cotidiano. Em sua ótica, a modernidade e seus regimes de representação provocam uma série de mudanças que afetam nosso sensorium, impactando as formas como experenciamos a experiência estética. Segundo o autor, é a partir do regime do sensível que ao construir modos de vida possíveis, ordenamos o mundo em que vivemos. Para ele, a partilha do sensível, portanto, produz sensação e interpretação do mundo:

Essa repartição das partes e dos lugares se fundam numa partilha de espaços, tempos e tipos de atividades que determina propriamente a maneira como um comum se presta a participação e como uns e outros tomam parte dessa partilha (Rancière, 2005, p. 15).

Nesse entendimento, podemos conceber que a partilha do sensível, proposta pelo autor, atravessa cortes de classe, gênero e raça, adquirindo dimensão política ao versar sobre o modo como o comum está sendo distribuído: "O que essas imagens falam? E por outro lado, o que elas silenciam?” Na ótica de Rancière (2005), estas dinâmicas pressupõem um regime estético que define quem é ou não visível no espaço comum.

No âmbito midiático o debate estético e seus desdobramentos configuram-se como importantes subsídios para se pensar a política, as subjetividades e os modos de exercer cidadania na atualidade. Omar Rincón (2006) situa a estética enquanto um acontecimento comunicacional, que emerge de produtos midiáticos, como por exemplo as narrativas do entretenimento televisivo.

Assim, as audiovisualidades colocam-se como territórios simbólicos da construção do comum ao suscitarem discussões sobre representações, sobre a relação com a arte, além também de atuarem como forma de refletir criticamente sobre o conteúdo imagético produzido pelos meios de comunicação e o quanto tais produções tem servido ou não a emancipação política e a diversidade ou, ao contrário, estão reiterando privilégios, preconceitos e promovendo o esvaziamento do debate artístico e estético.

Douglas Kellner (2001) insere as discussões estéticas no contexto da cultura midiática. Para o autor, a base da mídia é o audiovisual e, portanto, é estética. A seu ver, a estética midiática é a do espetáculo, que se torna um elemento chave para a compreensão da cultura, da economia, da política etc. Ao pensar as produções televisivas voltadas ao entretenimento, mas também as peças publicitárias, Kellner entende que tais narrativas fornecem modelos de identidades, solucionam contradições sociais e enaltecem a ordem social vigente. Dessa forma, ele compreende que a cultura midiática ocupa e transforma 
o cotidiano ao adquirir função modelar de veicular e, por vezes, reiterar lutas e discursos sociais existentes, dando sentido ao mundo (Kellner, 2001).

O autor parte da concepção de uma estética degradada, incapaz de proporcionar uma experiência libertária, já que a cultura midiática tende a colonizar nosso tempo livre, diminuindo as possibilidades de brecha pela via da estética. Esse processo, segundo o autor, ocorre a partir de uma linguagem sedutora que adula os sentidos, e nos curva as ideologias tecnocapitalistas (Kellner, 2001). Dessa forma, ao buscar a dimensão política dos produtos audiovisuais, o autor defende a crítica da mídia e a literacia midiática, como aspectos fundamentais para uma sociedade democrática que seja capaz de promover experimentações libertárias pela via da experiência estética.

Do mesmo modo, Andreas Huyssen (1987) parte da cultura midiática para discutir questões atreladas à estética. Em sua visão, os processos de globalização provocaram mudanças sociais tão profundas que deram origem a um novo cenário de configurações híbridas e fronteiras geográficas e culturais borradas. Como consequência, passamos a existir em um contexto de mesclas onde não faz sentido querer distinguir categoricamente entre "arte elevada" e cultura de massa. Isto porque, a defesa genuína de uma arte não contaminada convive com a emergência de se compreender as expressões artísticas híbridas que surgem desses encontros.

Ao mencionar a cultura política do pop e suas potencialidades como configuradores de novos estilos de vida, Huyssen (1987) defende a aproximação entre arte e realidade, no intuito de entender o que as produções audiovisuais da cultura popular, que surgem dessas mesclas, geram na sociedade. Em outras palavras, o autor visa uma arte, ou uma estética, que seja capaz de realizar transformação social.

Na mesma direção, Sontag (1987) propõem que a arte não seja entendida a partir do que ela "significa", mas a partir do que realiza ou do que faz sentir. Para a autora, a ênfase de uma obra artística deve estar nas formas e nas experiências sensoriais que elas provocam, e não em seu conteúdo ou interpretação. Isto porque, a profusão de interpretações da arte na contemporaneidade "envenena nossa sensibilidade": "interpretar é empobrecer, esvaziar o mundo - para erguer um mundo "fantasmagórico de significados". É transformar o mundo nesse mundo!" (Sontag, 1987, p. 16). Em outras palavras, Sontag não se coloca contra a interpretação, mas sim contra maneiras totalizantes ou prescritas de se interpretar uma obra de arte.

Para a autora, no cenário atual, permeado pela cultura massiva, somos bombardeados por uma metralhadora audiovisual que sobrecarrega nossa capacidade sensorial. Nesse sentido, a sociedade moderna requer o desenvolvimento de novas formas que sejam capazes de modificar nossa consciência e organize novos modos de sensibilidade que recupere nossos sentidos esgotados.

Ao visar um "olhar artístico" para as produções midiáticas, Guimarães (2007) compreende que o valor "poético" ou "estético" pode estar presente, em qualquer localidade, desde um concerto de música clássica a um programa de TV ou telenovela, por exemplo. Seu ponto de vista defende, portanto, que a experiência estética, ao fazer refletir sobre as possibilidades comunicativas que as imagens provocam, longe de nos alienar, nos fixa a realidade (Guimarães, 2007). 
A autora, ao apresentar o conceito de "tecnoestética", desvincula a experiência estética de uma ideia de "pureza”. Ela reconhece o caráter híbrido dos processos comunicacionais no âmbito midiático, que a seu ver, dão origem a produtos audiovisuais que derivam ao mesmo tempo do massivo e do artístico. A aproximação entre tecnologia e arte, em seu entender, acarreta um enriquecimento das possibilidades artísticas.

Richard Shusterman (1998) ao versar sobre as produções culturais massivas, como as séries de TV, reconhece suas possíveis falhas estéticas, bem como as reiterações de processos de dominação, contudo, avalia seu potencial progressista e democrático, e sua capacidade de fornecer satisfação estética, mesmo que não necessariamente promovendo a libertação sociocultural dos grupos minoritários que as consomem. As artes populares podem sim, na perspectiva do autor, fornecerem desafios que engajem o intelecto, nos auxiliando a lidar com realidades complexas que abranjam diferentes níveis de significação. $\mathrm{O}$ valor de suas produções, segundo Schusterman, se legitima esteticamente nas experiências que oferecem a visão, a audição, além das práticas críticas que engendram (Shusterman, 1998). Omar Rincón (2006), ao se debruçar sobre os modos de construção das estéticas midiáticas, afirma que a comunicabilidade das formas de narrar se sobrepõem aos conteúdos propriamente ditos. Deste modo, ao olhar para as produções midiáticas, em sua dimensão utópica, entende que tais narrativas se constituem por conflitos e disputas de sentido em negociação, que se concretizam no momento da enunciação. Nesse âmbito, ao narrarmos, segundo o autor, criamos mundos possíveis e nesse sentido, a mídia se configura como espaço de "reconhecimento" desse comum, ao se tornar território da disputa do visível, do narrável e do reconhecido (Rincón, 2006). Para o autor, a estética está pautada na compreensão das ambivalências e ambiguidades próprias da indústria midiática, que atua enquanto território de construção de significações e confrontações da alteridade.

De diferentes perspectivas, ambos refletem sobre a relação entre experiência estética e as novas tecnologias comunicacionais na era da cultura popular massiva. Enquanto Guimarães (2007), está em busca de uma possível dimensão "artística", para as produções audiovisuais no contexto da comunicação e da mídia. Rincón (2006) por outro lado, ao se deparar com um contexto em que a vida se converte em espetáculo, olha para as narrativas midiáticas a partir de um olhar estético que permita debater o comum, o banal, em sua dimensão política. Shusterman (1998) do mesmo modo, ao aproximar tal debate da realidade cotidiana, entende que a experiência estética engloba também o social e o político, permitindo repensar a arte, enriquecendo seu papel e apreciação.

Por fim, a partir da reflexão aqui colocada, temos que a experiência estética está atrelada a ação política na medida em que nos permite ver "o que se pode ver e do que se pode dizer do que é visto, de quem tem a competência para ver e qualidade para dizer, das propriedades do espaço e dos possíveis do tempo" (Rancière, 2009, p. 17). Como coloca Rancière (2005), as pedagogias que promovam a emancipação intelectual não virão necessariamente de uma revolução nos moldes propostos pelo marxismo, isto porque, para além dos sistemas produtivos materializados nas mercadorias faz-se essencial pensar nos sistemas de representação (imagens) que eles geram. 


\section{O remix como operador estético e político}

Para a leitura de produtos culturais como Little Fires Everywhere e seus processos de criação de sentidos, partimos das reflexões sobre cultura remix, justificando-se, portanto, a seleção da obra literária e da produção audiovisual como fenômenos para a análise. Compreendemos, aqui, o remix para além de um modo de fazer estético (Navas, 2012). Partimos do seu entendimento como um operador que tem por base uma percepção modular da cultura (Manovich, 2001, 2005), e a atravessa, permitindo, portanto, uma reapresentação das audiovisualidades, de modo a suscitar novas partilhas do sensível (Rancière, 2005).

O remix tem por modus operandi as operações de copiar/recortar e colar textos e produtos audiovisuais, modificando-os e reordenando seus sentidos. Tais dinâmicas, evidenciam uma dimensão mais ampla da cultura, motivo pelo qual o conceito é denominado um "aglutinador cultural" (Navas, 2012). Estes processos podem ser percebidos nos mais diversos produtos culturais, produzindo novas significações derivativas, que podem incorporar elementos do texto original, mas que não se igualam e nem se limitam a este.

Por esta perspectiva, vemos na ideia de remix uma proximidade com o conceito de remediação proposto por Bolter e Grusin (2002), atinente às constantes referências e apropriações realizadas no âmbito dos produtos midiáticos. As referências, citações e apropriações são alguns dos princípios da remixagem que, argumentamos, permeiam e informam a cultura, e que parecem também agir sobre os constantes processos de remediação dos produtos midiáticos contemporâneos.

Assim, o remix pode ser capaz de deslocar posições já conferidas aos textos culturais sobre os quais se manifesta, evidenciando as partilhas do sensível que distribuem as posições e hierarquias dos contextos e significados atribuídos a esses textos culturais, o que se observa também nos processos de remediação. Identificamos, portanto, no remix um potencial político, ou uma politicidade, no sentido de Scudeller (2020); ao realizar um exercício estratégico de reposicionamento destes elementos e de reconfiguração do sensível, o remix pode exercer uma função simultaneamente estética e política, que propõe novos contextos, e confere novas legitimidades e visibilidades.

$\mathrm{Na}$ análise da obra literária e da adaptação para a TV, vemos que em Little Fires Everywhere os processos de significação operados são diversos, apesar das produções partirem de um mesmo texto base. Nesta perspectiva, vemos que é justamente no fluxo entre-mídias, no âmbito da transposição dos textos a uma nova matriz contextual, que estes processos se produzem, abrindo-se, portanto, ao nível da metalinguagem e pelo remix, novas brechas, novos espaços de questionamento e de atuação estético-política.

Rocha e Santos (2018) ao discutirem as produções audiovisíveis, a partir da ideia de remediação tecnoestética, também informada por Bolter e Grusin (2002), afirmam que a cultura potencialmente se remixa e que a descompressão dos polos emissores, promovida pela digitalização tecnológica, abre brechas que possibilitam "conduzir a outros devires - comunicacionais, culturais, existenciais, políticos” (Rocha, Santos, 2018, p. 207). Nesse entendimento, a presença de uma obra como Little Fires Everywhere no mainstream não necessariamente exclui suas potencialidades críticas, ao contrário, elas se expandem e se materializam na dimensão audiovisual. 
Para além da discussão da remixagem e da remediação, também nos valemos das reflexões rancierianas sobre a partilha do sensível para pensar as intersecções entre experiência estética, cultura midiática e representações da diferença. Tendo em vista que as audiovisualidades colocam-se como territórios simbólicos da construção do comum e, portanto, o debate estético e seus desdobramentos no âmbito midiático configuram-se como importantes subsídios para se pensar a emancipação política e a diversidade na contemporaneidade.

\section{Análise das narrativas da diferença presentes em Little Fires Everywhere: uma abordagem interseccional}

As narrativas presentes tanto na produção audiovisual como na obra literária exploram a relação entre duas famílias, principalmente entre as duas matriarcas, Elena e Mia. De início, é possível perceber dois modelos distintos de família sendo colocados. Enquanto os Richardson representam um tipo entendido como mais 'tradicional': mãe e pai, casados, com bons empregos e condições financeiramente estáveis, quatro filhos e morando em uma mansão; os Warren aparecem como uma categoria menos conservadora: mãe solteira, modo de vida errante, sem uma casa fixa; trabalhos informais e precarizados e uma filha sem muito conhecimento sobre a história de seu pai.

Kimberley (2017) aborda o conceito de interseccionalidade, a partir da interação entre gênero e raça, como as evidenciadas nas personagens de Elena e Mia, em Little Fires Everywhere (Figura 1). A autora afirma que esses aspectos sociais afetam a vida de mulheres e deixa claro a necessidade de que a dimensão dessas experiências não seja examinada separadamente, mas em seus entrecruzamentos.

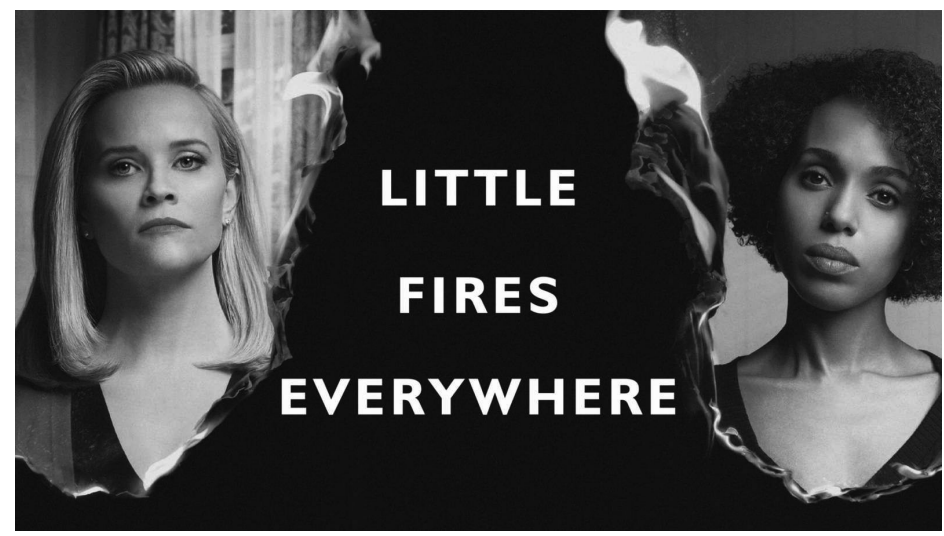

Figura 1: As protagonistas Elena e Mia. Fonte: https://www.folhacg.com.br/na-poltronado-cinema-com-pedroka/little-fires-everywhere-colisao-de-duas-familias/ 
$\mathrm{Na}$ história, as famílias das personagens se cruzam quando Elena, na intenção de fazer caridade para com aquela família que ela julga necessitada e inferior socialmente, oferece uma casa com um valor bem abaixo de aluguel para Mia e Pearl Warren morarem, iniciando-se aí uma relação de afeto entre os personagens. Os filhos das protagonistas se aproximam e passam a conviver (Figura 2), enquanto as mulheres passam a vivenciar uma série de conflitos que expõem diversos aspectos referentes as diferenças de classe, raça e gênero entre elas, algo que se torna mais evidente na produção audiovisual.

Elena sofre julgamentos no trabalho por ter tido vários filhos e ter menos tempo para se dedicar à carreira de jornalista, profissão que exerce em um veículo de imprensa local. Fica nítida também a cobrança que sofre socialmente em seu entorno para que atinja uma espécie de ideal de perfeição para todas as funções que exerce "mãe, esposa e mulher", algo que, em vários momentos, demonstra sufocá-la.

Os valores morais de Elena também são problematizados ao longo da narrativa. Evidencia-se todo um conjunto de regras que norteia sua vida e entendimento enquanto mulher, mãe e esposa. A repressão de sua sexualidade é demonstrada em vários momentos, como na dificuldade em dizer em voz alta aspectos relacionados ao seu órgão genital e a refletir sobre a busca do próprio prazer; além do fato de estabelecer dias certos para se relacionar sexualmente como o marido (quartas e sextas) e a cobrança em renunciar aos próprios sonhos e vontades em favor da maternidade.
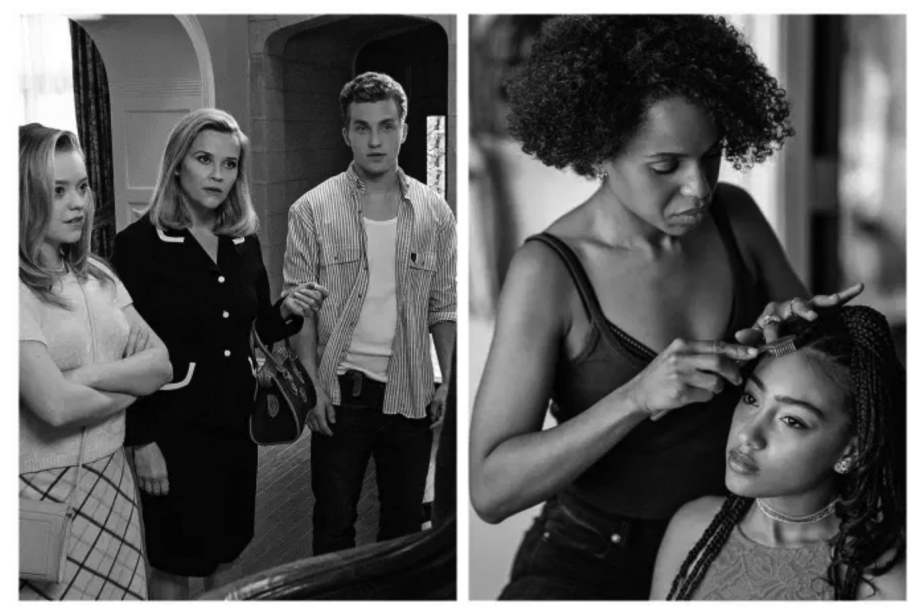

Figura 2. Cenas das personagens com seus filhos. Fonte: https://veja.abril.com.br/blog/isabelaboscov/pequenos-incendios-por-toda-parte-e-nova-empreitada-de-reese-whiterspoon/ 
Mia, por outro lado, renuncia a um lar mais confortável e a uma vida economicamente mais estável para si e para a filha em prol da realização pessoal na carreira de artista plástica. A arte, inclusive, funciona para ela como uma forma de exercer sua liberdade, de expressar a forma como enxerga o mundo e as pessoas, suas dores e angústias, mais do que propriamente como uma forma de subsistência. $\mathrm{O}$ salário que a mantém, vem do emprego como garçonete em um restaurante chinês. $\mathrm{O}$ trabalho, para Mia, é visto como algo que se distingue da realização pessoal, mas, algo que se faz por necessidade de sobrevivência. A liberdade também é algo presente na forma como Mia lida com o próprio corpo e com suas relações amorosas. Para ela, o prazer sexual e o valor afetivo nem sempre estão atrelados a relações monogâmicas, estáveis e heterossexuais.

A intersecção com a raça é o que mais expõe os conflitos entre a vivência das duas protagonistas. Importante notar, entretanto, o imenso impacto que se verifica na remediação da obra literária em sua versão audiovisual: a protagonista Mia e sua filha Pearl não são racializadas na primeira, centrando-se a questão racial nos eventos correlatos à disputa pela guarda de uma criança chinesa, entre sua mãe biológica, que é amiga de Mia, e a mãe adotiva, amiga de Elena.

No entanto, na adaptação audiovisual, as personagens Mia e Pearl são marcadamente negras, e em decorrência especificamente deste fato, há uma nova dimensão sensível que torna-se primordial na recepção deste produto, uma vez que se instauram notáveis diferenças semânticas e sensíveis no que tange à questão racial: a personagem Mia, já no primeiro episódio, depara-se com policiais questionando sua simples presença no condomínio à janela de seu carro, uma cena comum na realidade de afro-americanos, por vezes denunciada pelos movimentos negros nos Estados Unidos por atrelarem negritude a imagem de "alguém suspeito". Outro fato mostrado na série é o momento em que Elena se dispõem a "ajudar" Mia financeiramente. Elena propõe que Mia limpe sua casa; a proposta tem um peso bastante diverso daquela realizada no contexto da obra literária, e que é explicitada pela reação de Elena ao perceber que sua proposta pudesse conter algum racismo, ficando constrangida. Elena, como mulher branca e privilegiada financeiramente, por vezes, é incapaz de compreender as escolhas e desafios de Mia. Em vários momentos ela expõe seu racismo e classismo como quando busca, sem motivo aparentemente, a ficha criminal da inquilina na desconfiança de que ela possa ter cometido crimes por ser negra e pobre. Na série audiovisual, isto se torna ainda mais evidente, como quando, no intuito de soar inclusiva, diz para o namorado da filha e para Pearl, que haviam acabado de se conhecer, que eles teriam muito em comum, unicamente por serem negros. A personagem também defende ideias meritocráticas como "se não pode dar conta de ser mãe, não fique grávida" ou "não se pode punir jovens só porque seus pais fizeram boas escolhas e não se viciaram em crack" ignorando aspectos como a diferença de oportunidades e a desigualdade social e racial.

\section{Considerações finais}

Em virtude da análise exposta, consideramos que a remediação da obra literária em produtos audiovisuais traz à tona algumas dimensões significativas no que tange aos mar- 
cadores de gênero, classe e raça, e que nos permitem desenvolver e identificar algumas narrativas fundamentais à visibilidade de uma luta interseccional. Fica explícito, em Little Fires Everywhere, principalmente em sua adaptação para a TV, uma tentativa de dar visibilidade a narrativas que abordem múltiplos sistemas de opressão nas representações das personagens femininas.

É neste sentido que vemos a grande potência política do remix e da remediação, que podem ser -e aqui argumentamos que são- capazes de trazer à tona narrativas frequentemente apagadas, promovendo novas partilhas do sensível. Aqui, podemos afirmar que elas se evidenciam em três níveis. O primeiro diz respeito ao no nível da legitimidade, sobre o que e quem pode ou não ser considerado quando da divisão deste comum partilhado. Aqui fala-se da legitimação dos sujeitos representantes e representados, e das narrativas trazidas à tona em uma certa divisão do sensível.

O segundo nível diz respeito à representatividade. Angela Davis (2016) afirma que conquistar representatividade em espaços de poder, como nas produções audiovisuais, é essencial para a luta contra a opressão. Contudo, mais do que ocupar lugares, faz-se essencial um real comprometimento com o rompimento das lógicas de opressão. Assim, a remediação de Little Fires Everywhere nos parece também ter contribuído para a ocupação destes territórios midiáticos, e da denúncia clara que emerge a partir da inclusão das opressões interseccionais como narrativas das personagens. Vemos que a brecha semântica e sensível que se dá entre o texto literário e a série audiovisual é também mais uma evidência da politicidade destes vazios, que, uma vez ocupados, podem complexificar interpretações e ser um lócus de atuação política.

Finalmente, o terceiro nível diz respeito à visibilidade. Aqui nos valemos da diferenciação que realiza Rose de Melo Rocha entre visualidade e visibilidade, afirmando que a "visibilidade se associa, portanto, a mecanismos socioculturais partilhados que conferem, a determinadas imagens visuais, a qualidade de partícipes de sistemas de crença e de leitura visual reconhecíveis e reconhecidos" (Rocha, 2006, p. 10). Assim, a visibilidade se relaciona mais diretamente às escolhas políticas, a uma "visualidade portadora de legibilidade", e que diz respeito à uma credibilidade socialmente estabelecida. Em Little Fires Everywhere, vemos que as questões interseccionais são trabalhadas de modo a darem visibilidade a situações que outrora teriam sido apagadas, por meio de uma remediação tecnoestética que permitiu, aqui, que se conduzissem as narrativas a outros territórios e a outros devires.

\section{Notas}

1. Este artigo é o desenvolvimento de uma versão preliminar deste mesmo trabalho, a qual fora apresentada na Mesa 8: Prácticas artísticas, estéticas e industrias culturales do IV Congreso de Comunicación y Ciencias Sociales desde América Latina (IV COMCIS), organizado pela Universidad Nacional de La Plata, Argentina, em outubro de 2020. 


\section{Referências}

Bolter, J. D. e Grusin, R. (2002). Remediation. Understanding New Media. Cambridge, Mass.: The MIT Press.

Collins, P. H. e Bilge, S. (2020). Interseccionalidade. São Paulo: Boitempo.

Davis, A. (2016). Mulheres, raça e classe. São Paulo: Boitempo.

Guimaraes, D. A. D. (2007). Comunicação tecnoestética nas mídias audiovisuais. Porto Alegre: Sulina.

Huyssen, A. (1986). After the great divide. Modernism, mass culture, postmodernism. Bloomington: Indiana University Press.

Kellner, D. (2001). A cultura da mídia. Bauru: EDUSC.

Navas, E. (2012). Remix Theory: the aesthetics of sampling. Viena/Nova York: Springer.

Manovich, L. (2001). The Language of the New Media. Cambridge/Londres: The MIT Press. (2005). "Remixability and Modularity”. Disponível em: http://manovich.net/ content/04-projects/046-remixability-and-modularity/43_article_2005.pdf

Ranciére, J. (2005). A partilha do sensível: estética e política. São Paulo: EXO Experimental / Editora 34.

Rincón, O. (2006). "Narrativas mediáticas, O cómo se cuenta la sociedad del entretenimento", col. Estudios de televisión, núm. 23. Barcelona: Gedisa.

Rocha, R. M. (2018). "Remediação com purpurina: bricolagens tecnoestéticas no drag-artivismo de Gloria Groove”. Revista Interin, v.23, n.1., jan/jun 2018, p.205-220. Disponível em: https://pdfs.semanticscholar.org/bf9c/153cc1b1302b7d00bb1412f3192d5451d610.pdf. (2006). "Cultura da visualidade e estratégias de (in)visibilidade". E-Compós, v. 7, 26 jun. 2006. Disponível em: https://www.e-compos.org.br/e-compos/article/ view/115/114.

Scudeller, P. A. P. (2020). Curadoria Remix : reflexões sobre circulação e consumo de arte na $33 a$ Bienal de São Paulo. Dissertação (Mestrado em Comunicação e Práticas de Consumo. Programa de Pós-Graduação em Comunicação e Práticas de Consumo - Escola Superior de Propaganda e Marketing, São Paulo.

Shusterman, R. (1998). Vivendo a arte. O pensamento pragmatista e a estética popular. São Paulo: Editora 34.

Sontag, S. (1987) Contra a interpretação. Porto Alegre: L\&PM.

Resumen: Este artículo propone, a partir de un análisis comparativo entre el bestseller Little Fires Everywhere y su adaptación para televisión, tensar los sentidos relacionados a marcadores de género, raza y de clase presentes en sus narrativas. Buscamos comprender cómo se incorporan y negocian las narrativas de la diferencia en estas obras, a partir de reflexiones sobre la cultura remix, e identificar en qué medida las narrativas revelan regímenes de visibilidad y se convierten en operadoras de disenso, estableciendo una política de diferencia respecto a las representaciones femeninas. Pensamos en las intersecciones entre experiencia estética, cultura mediática y representaciones de la diferencia. 
Palabras clave: audiovisibilidad - cultura remix - representaciones de la diferencia - reparto de lo sensible - Little Fires Everywhere.

\begin{abstract}
This article proposes a comparative analysis of the bestseller Little Fires Everywhere and its adaptation for television, tensioning meanings and interpretations related to the gender, race and class markers present in their narratives. We seek to understand how the narratives of difference are incorporated and negotiated in these works, based on reflections on remix culture, and to identify the extent to which narratives reveal regimes of visibility and become operators of dissent, establishing a policy of difference in relation to female representations. We think here of the intersections between aesthetic experience, media culture and representations of difference.
\end{abstract}

Keywords: audiovisibilidade - remix culture - representations of difference - distribution of the sensible - Little Fires Everywhere.

[Las traducciones de los abstracts fueron supervisadas por el autor de cada artículo] 